\title{
Rationing the Pressurized Air-Vessel Volume for Water Hammer Protection in Water Pipe Systems
}

\author{
Ahmed El-Dabaa, ${ }^{1, *}$ Osama Khorais ${ }^{2}$ \\ ${ }^{1}$ Mechanical Engineer, Hydraulics Research Institute \\ National Water Research Centre, Egypt \\ ${ }^{2}$ Assistant Prof., Mataria Faculty of Engineering \\ Helwan University, Egypt \\ * Corresponding author's email: a.eldabaa [AT] gmail.com
}

\begin{abstract}
Air vessel is one of the efficient devices for controlling and protecting the piping system against transient problems as water hammer phenomenon. Old studies illustrated the air vessel importance and its working methodology. In order to maximize the performance and minimize the hazardous problems of such system, protection devices (such as air vessel) cost is one of the considerations in the design process. Therefore, its characteristics are highly important for efficient operation with less expensive safety system. This research paper presents a numerical modelling work to investigate the effect of the Air Vessel parameters, such as (1) dimensions (diameter, D, height, $H$ ), (2) the connection equivalent resistance, hlc, between the vessel and the main pipeline and (3) initial state parameter (initial air volume, Vai). Those parameters affects the vessel total volume (Vt) and operation as well as the safety system. A pump station is simulated as a case study using Wanda model. The results showed that the specifications change in vessel height, $\mathrm{H}$, connection equivalent resistance, hlc, with main pipe and initial air volume, Vai, have a great impact on the system protection against transient problems when using the air vessel.
\end{abstract}

Keywords--- Air Vessel, Water Hammer, Pipe Line, Surge Pressure

\section{INTRODUCTION}

In order to participate in implementing the Egyptian government plan to increase the cultivated and urbanized areas, water piping systems are commonly used for handling water between sources and new desired areas with the benefit of decreasing wasted water during this handling. Hence, water pipeline systems are became more vital infrastructure that provide an indispensable public service to the society, and their operation are became more complex. However, these systems are subjected to several problems such as pressure surges because of pumps' start-up and trip-off or maneuvers in mechanical devices. The prediction of pressure surges is important in the design of water pipeline systems for the selection of pipe materials, pressure classes and surge protection devices. When severe transients cannot be avoided, or the pipe layout or parameters are changed (e.g., operating conditions), surge protection devices should be double-checked with specification to sustain maximum and minimum pressures within acceptable limits.

Usually, the decision is the most economical and reliable solution that yields an acceptable transient pressure response. Hydraulic transient analysis is important for the diagnosis of existing operational problems (e.g., pipe failures, devices malfunctioning). Consequently, there is a need for increasing the technical studies with more focusing on how to eliminate those transient problems. A numerical model of a piping system located in Elshapap area Elsharkia government Egypt was executed applyingWanda4.1program.

\section{BACKGROUND}

At the beginning of the nineteenth century with considering fluid and pipe wall elasticity Joukowsky 1904 started the analysis of water hammer and showed that the pressure rise in a water line depends on the change in the flow velocity, the wave speed and fluid density. Italian Allievi 1925, developed a mathematical and graphical treatment of water hammer problems. His study was the foundation for further developments in this field for the following fifty years. Upon the work of Joukowsky 1904 and Allievi 1925 several studies were carried out using the graphical technique of analysis such as those conducted by, Angus 1935 and Bergeron 1961.

In 1967 Streeter introduced the application of the computer as a comprehensive water hammer analysis, which is innovated with the study of Wylie 1993. The work of Streeter 1967, together with the work of Alllevi 1925, and Joukowsky 1904 has made a major contribution to the analysis of the transient flow. Wylie EB, Streeter VL (1993), A.S.

Tijsseling 2007 conducted such models taking into account fluid-structure interaction. A one-dimensional mathematical model was presented which described the acoustic behaviour of thick-walled liquid-filled pipes. The model 
was based on conventional water hammer and beam theories. In two-part paper Anton Bergant, et al, 2008 investigated key parameters that may affect the pressure waveform predicted using the classical theory of water-hammer. David Stephenson 1997 carried out a study for more concentration in parameters could affect water hammer such as pipe wall material, pipe wall thickness, pipe containment and effect of air in the pipe in order to correct selection of air valve size and standpipe used to minimize water hammer.

Because of the complexity of the equations needed to describe transient flow, and due to the technology development, several numerical computer models were developed and used to analyze transient flow hydraulics. An effective numerical model allows the hydraulic engineer to analyze potential transient events and to identify and evaluate alternative solutions for controlling pressure transients, thereby protecting the integrity of the hydraulic system. M.A. Bouaziz, et al, used a numerical computer model to simulate the propagation of pressure waves in water gray cast iron pipe systems. The pressure waves are caused by the water hammer phenomenon due to fast valve maneuvers in the pipe network.

In 2011 Hasan used a numerical computer model Wanda V3.03 to improve the design of irrigation pipeline networks due to pump power failure. This study investigated the effect of using several protection devices on the unsteady flow as (1) air vessel only, and (2) air vessel with surge tank; on the network. It was found that using the proposed air vessel only proved to be effective for preventing column separation. Using of air vessel with surge tower were becoming more effective, and decreased the size of the initial air vessel comparing with the $1^{\text {st }}$ case.

In 2014 Keller used numerical computer model to investigate severe water hammer in Hoppers crossing pumping station. Transient simulations were undertaken using the PIPE2012 program model utilizing the SURGE engine to avoid unacceptable transients those appear during commissioning tests. This simulation was conducted to demonstrate the potential severe transients that may occurred in the rising mains. The particular incident occurred during rapid pump delivery valve closure on one pump. It was shown that unacceptable transients could be avoided, even during rapid total valve closure, if the valve was closed very rapidly over the first $72 \%$ and slowly over the final $28 \%$ of closure.

Bandy Opadhyay 2014, used three different hydraulic models, EPANET, Water Gems and Bently Hammer program models to analyze raw water intake piping system of Mejia Thermal Power Plant. He tried to overcome water hammer waves by putting a surge tank at different distances in the main pipe and he found that water hammer pressure decreasing when the junction of the surge tank distance increase.

Akpan 2015, conducted an investigation by using Wanda program. His simulation results showed that it was reasonably accurate to approximate the air behavior in air vessel used for water pipeline protection systems, by using a rigid column analysis, as this simplified the problem and saved computational time. The same cannot be said for the pipeline pressure head envelope predictions, as the water hammer analysis was still more accurate. Even the elasticplastic behavior of welded joints during loading and unloading of pressure vessel had been analyzed in the work of Simon Sedmak et al. in 2016.

From the above history of research in water hammer problem, several parameters have been investigated to study the effect of using the air vessel with and without the existence of the other devices such as air vent, or surge tower. In this study, the research is focusing on the parameters that affect the air vessel efficiency, such as vessel dimensions $(\mathrm{H}$, $\mathrm{D}, \mathrm{V}$ ) and the vessel connection with pipeline.

\section{OBJECTIVES}

In order to maximize vessel controlling performance, eliminating water hammer in pipeline system and minimizing the vessel initial cost, this study is concentrating on studying the parameters that affect the air vessel operation performance, those parameters are summarized as:

1- Air vessel geometrical dimensions characteristics, (height, H, diameter, D)

2- Initial air volume in the vessel, $\mathrm{V}_{\mathrm{ai}}$.

3- The connection resistance between vessel and pipeline, $\mathrm{h}_{\mathrm{lc}}$.

\section{METHODOLOGY}

In this investigation, Wanda 4.1 was used as a mathematical simulation model to study the different parameters changes. This investigation was conducted in Hydraulics Research Institute. Data of selected pump stations were collected by field visits and disk study. A validation technique was conducted by simulating a piping system in Elshabab area, Bilbis, Elshaqia, and the results showed good agreement. After modeling and validating the system, several model scenarios were developed to achieve the study objectives, these scenarios are:

1- 23 system runs were introduced by tuning the ratio of vessel height to diameter $(\mathrm{h} / \mathrm{d})$, from lowest ratio $=0.62$ at diameter $5 \mathrm{~m}$ to largest ratio 35.37 at diameter $1.3 \mathrm{~m}$. 
2- 24 system runs were investigated by tuning the ratio of initial air volume to total vessel volume $\left(\mathrm{V}_{\mathrm{ai}} / \mathrm{V}_{\mathrm{t}}\right)$ this ratio tuned in from largest ratio $21.31 \%$ while the vessel could operate without empting the chamber from water to lowest ratio $0.82 \%$ where the vessel approximately filled with water.

3- 22 system runs were studied by tuning the ratio of Vessel connection equivalent resistance to vessel upstream working pressure head, $\left(\mathrm{h}_{\mathrm{lc}} / \mathrm{P}_{\mathrm{w}}\right)$, from lowest ratio $=0.1$ to largest ratio $111.9 \%$.

A comparative study was executed for each parameter ratio, versus the initial ratio using diagrams of the change in pressure from the initial case versus the ratio change, and pressure during run time at the most affected point in the pipeline (weak point location at $2.25 \mathrm{~K} . \mathrm{m}$ from pipeline inlet point) in each case compared to the initial case.

\section{CASE STUDY}

In order to investigate the effect of the selected parameters, a mathematical model was developed for a system consists of Pump station in El-Shabab area in Abo Hamad city, El Ismaeilia that had 5 pumps (4duty + 1spair). This model was used to deliver water from El-Shabab channel to a collector tank throw pipes with 4.5Km length. Pumps and pipes specifications are as below:-

\subsection{Pumps Description}

$\begin{array}{llll}\text {-Number of pumps : } & 5(4+1) \text { units } & \text {-Discharge (Duty point) : } & 1 \mathrm{~m}^{3} / \mathrm{Sec} \\ \text {-Type : } & \text { Vertical pumps } & \text {-Manometric head(Duty point) : } & 57 \mathrm{~m} \\ \text {-Nominal power : } & 682 \mathrm{KW} & \text {-Efficiency : } & 82 \% \\ \text {-R.P.M : } & 9941 / \mathrm{min} & \text {-Polar moment of inertia : } & 115 \mathrm{Kg} . \mathrm{m}^{2}\end{array}$

\subsection{Pipe lines Description}

$\begin{array}{llll}\text { Number of Pipes : } & 2 \text { lines } & \text {-Pipe material : } & \text { Pre-stressed concrete } \\ \text { Pipeline profile : } & \text { in Fig(1) } & \text {-Wave speed : } & \approx 1000 \mathrm{~m} / \mathrm{sec} \\ \text { Young modulus : } & 2.1 * 10^{10} \quad \mathrm{~N} / \mathrm{m}^{2} & \text {-Pipe diameter : } & 1000 \mathrm{~mm} \\ \text { Pipe working pressure : } & 10 \text { par } & \text {-Pipe thickness : } & 100 \mathrm{~mm}\end{array}$

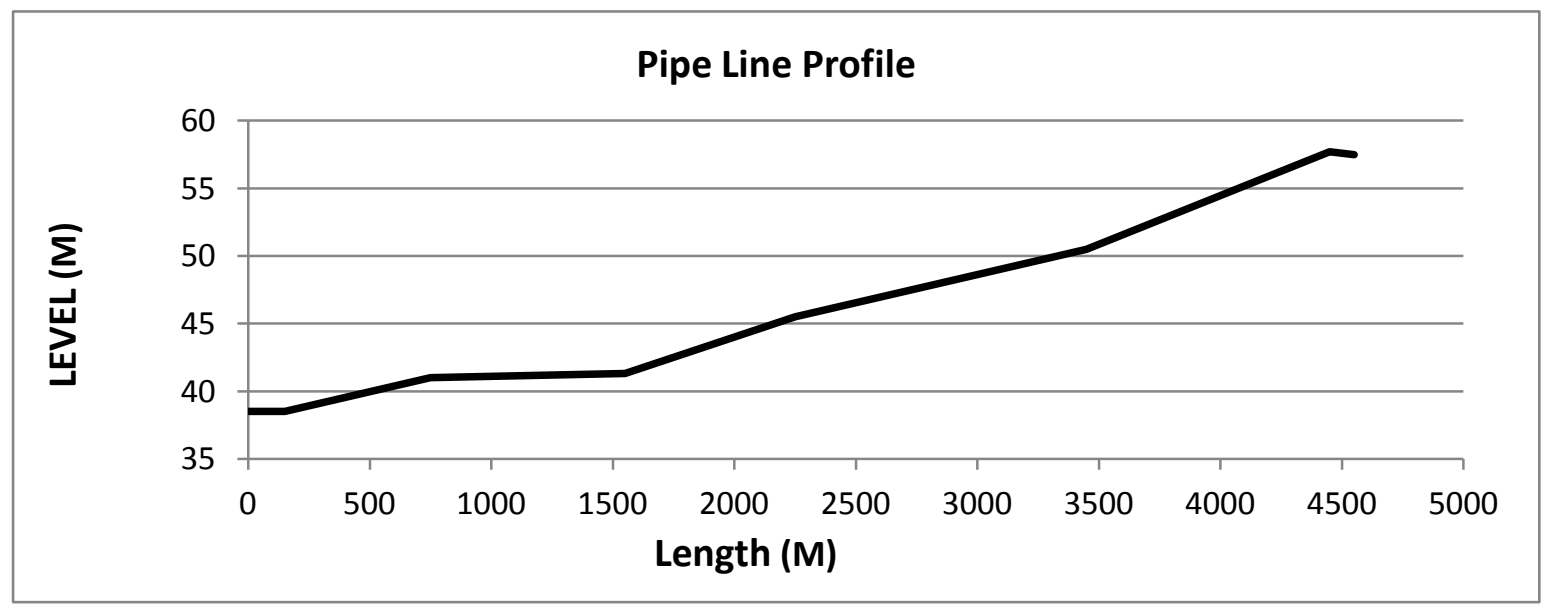

Figure 1 Pipe Line Profile

\subsection{Safety system}

In the current study, the system consists of one pipeline with its two pumps and an equivalent air vessel with the same total volume of $61 \mathrm{~m}^{3}$. 


\section{a. Equivalent Air Vessel}

- Tank total volume $=61 \mathrm{~m}^{3}$

- $\quad$ Vessel bed level $=40 \mathrm{~m}$

- $\quad$ Height of vessel $=8.63 \mathrm{~m}$

- $\operatorname{Initial}\left(\mathrm{V}_{\mathrm{ai}} / \mathrm{V}_{\mathrm{t}}\right)=19.02 \%$
- Initial Air Volume

- Diameter of vessel

- Initial (h/d)

- Initial $\left(\mathrm{h}_{\mathrm{lc}} / \mathrm{P}_{\mathrm{wi}}\right)$

$$
\begin{aligned}
& =1.6 \mathrm{~m}^{3} \\
& =3 \mathrm{~m} \\
& =2.88 \\
& =0.74 \%
\end{aligned}
$$

\section{MODEL VALIDATION}

The model was investigated first to validate the accuracy of the results to make sure that the model meets correctly the investigated parameters. The validation was based on data recorded from the field in HRI report N0_(155/2013). The measured pump discharge and pressure head were $1.03 \mathrm{~m}^{3} / \mathrm{S}$ and $55.6 \mathrm{~m}_{\mathrm{H} 2 \mathrm{o}}$ respectively at the steady state operation case, while the resulted pressure head at the same case in the model were $1.02 \mathrm{~m}^{3} / \mathrm{s}$ and $55.58 \mathrm{~m}_{\mathrm{H} 2 \mathrm{o}}$ respectively. This means an error of less than $1 \%$ in discharge readings and $0.04 \%$ in pressure head. In case of power sudden failure the measured pressures due to water hammer were $8.15 \mathrm{Bar}$ at pipe line inlet point and $-0.39 \mathrm{Bar}$ at $2.25 \mathrm{Km}$ (weak point) from the pipe line inlet point. Where the resulted pressure in the model was 8.2 Bar at pipe line inlet point and -0.3861 Bar at the weak point from the pipe line inlet point. Which means an error of less than $1 \%$ in pressure head readings.

Figures 2, 3 show a relations predicted by Wanda model. Figure 2 shows a relation between the pressures along the pipe line and the distance from the pipe inlet point. This figure shows three lines; the middle solid line refers to pressure distribution along the pipe line at steady state operation, the upper and lower dotted lines are referring to the maximum and minimum pressure distribution along the pipe line in the unsteady state case (pump power sudden failure). Figure 3 shows a relation of pressure versus time at the selected weak point. This figure illustrates the change in pressure head at the weak point during the run time.

As shown from table 1 the deviation adopted of pump out pressure in Wanda model is about $0.952 \%$ from the measured data and $0.99 \%$ for the pipe inlet point while it was $0.277 \%$ at the weak point.

\begin{tabular}{|c|c|c|c|c|c|c|c|c|c|c|}
\hline & location & Pump & & & Upstre & Pipelin & & Weak poi & & \\
\hline \multirow[b]{3}{*}{ 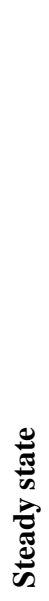 } & \multirow{2}{*}{$\frac{\substack{0 \\
0}}{2}$} & 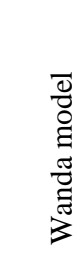 & 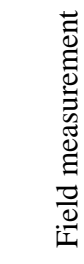 & 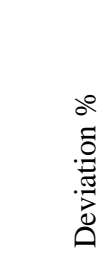 & 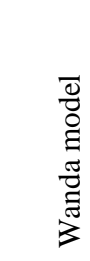 & 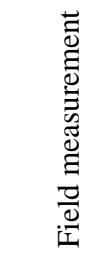 & 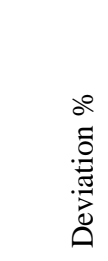 & $\begin{array}{l}\bar{\Xi} \\
\overline{0} \\
\Xi \\
\bar{\Xi} \\
\bar{\Xi} \\
3\end{array}$ & 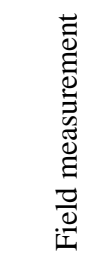 & 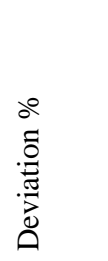 \\
\hline & & 1024 & 1030 & 0.586 & 2047 & 2060 & 0.635 & 2047 & 2060 & 0.635 \\
\hline & 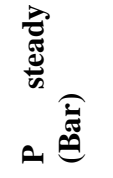 & 5.25 & 5.3 & 0.952 & 5.037 & 5.1 & 0.990 & 2.892 & 2.8 & 0.277 \\
\hline \multirow{2}{*}{ 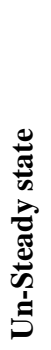 } & م & 5.25 & 5.3 & 0.952 & 8.241 & 8.3 & 0.716 & 4.773 & 4.8 & 0.566 \\
\hline & 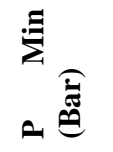 & -0.2 & -0.2 & 0.00 & -0.26 & -0.26 & 0.383 & -0.38 & -0.39 & 1.01 \\
\hline
\end{tabular}

The previous analysis shows a very good agreement between the results obtained from Wanda model and the measured data, which means that the model is good valid to be used in investigating unsteady pipeline analysis.

Table 1. The deviations adopted between the measured data from the field and Wanda program output data. 


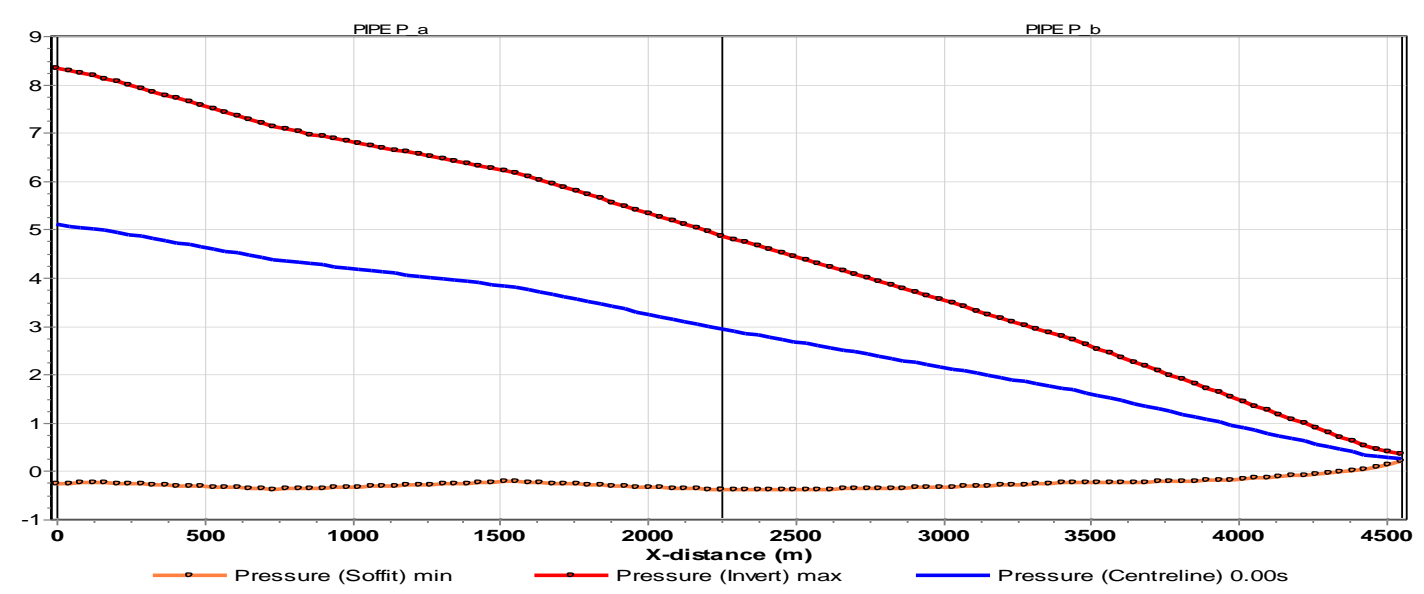

Figure 2 Pressure distribution along pipeline

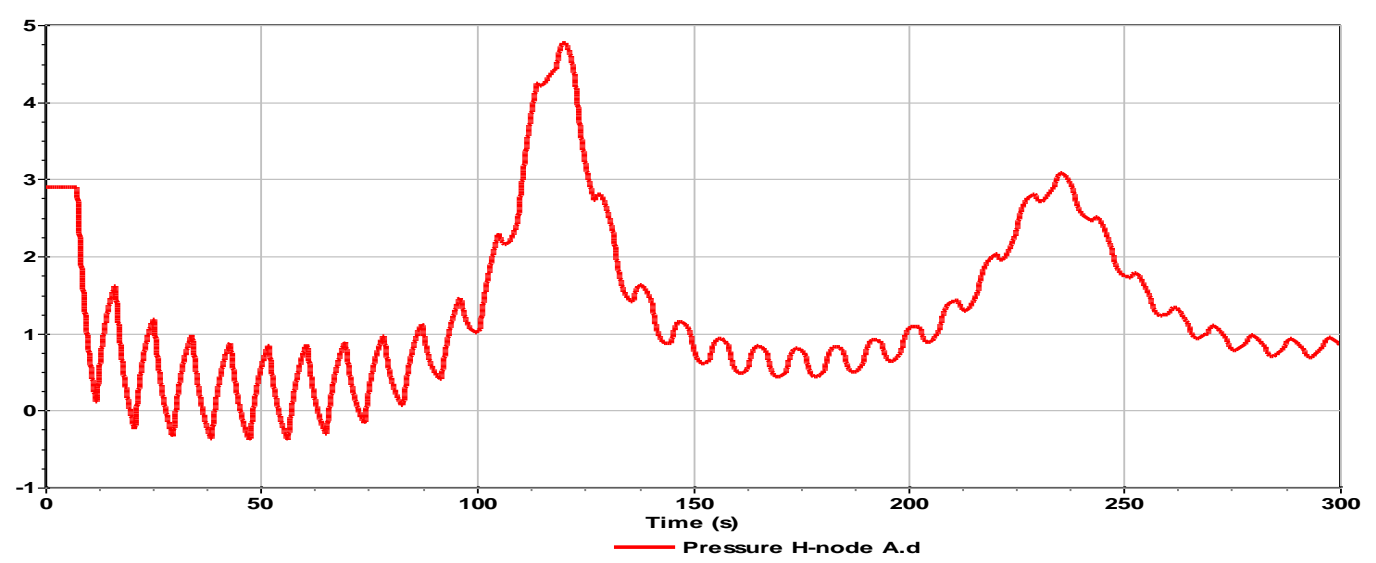

Figure 3 pressure versus time at weak point

\section{MODEL SCENARIOS}

Three different scenarios were developed in order to investigate the effect of the air vessel geometrical design on the safety system efficiency, as will be discussed in the coming section.

\subsection{Air vessel dimensions}

A reference tank volume was selected to compare the changes in pressures related to the changes of vessel dimensions with those obtained from the existence of reference tank. Reference tank specifications was mentioned previously in section 6.3. In order to investigate the effect of the air vessel dimensions (Height and diameter), with respect to the reference volume of the vessel, different heights and diameters had been applied in 23 runs from lowest ratio of $\mathrm{h} / \mathrm{d}$ equal 0.62 at diameter $5 \mathrm{~m}$ to largest ratio 35.37 at diameter $1.3 \mathrm{~m}$.

Fig 4 illustrates the change of pressure at the week point represented in percentage from the initial value due to the change in the ratio $\mathrm{h} / \mathrm{d}$. Also it shows that by increasing the ratio $\mathrm{h} / \mathrm{d}$, the minimum pressure during the run time at the weak point $(2.25 \mathrm{~km})$ decreased by $-56 \%$ at the case of $\mathrm{h} / \mathrm{d} 35.37$, while the maximum pressure at the same point reduces by $-37.8 \%$ at the case of $\mathrm{h} / \mathrm{d} 35.37$. It also was found that by reducing the ratio $\mathrm{h} / \mathrm{d}$, the minimum pressure during the run time at weak point raised by $7.5 \%$ at the case of $\mathrm{h} / \mathrm{d} 0.62$. While the maximum pressure at the same point raised by $4.3 \%$ at the case of $\mathrm{h} / \mathrm{d} 0.62$.

Figure 5 shows the change of pressure versus time due to the pump power sudden failure at the week point. It shows a good effect on the maximum and minimum pressures values with $\mathrm{h} / \mathrm{d}=35.37$ compared to other cases $(\mathrm{h} / \mathrm{d}=0.62, \mathrm{~h} / \mathrm{d}$ = initial). The maximum pressure is decreased to 2.9 bar and the minimum pressure is reduced to -0.17 bar from the initial values. It also shows a time delay for both peak and minimum values of the pressure. 


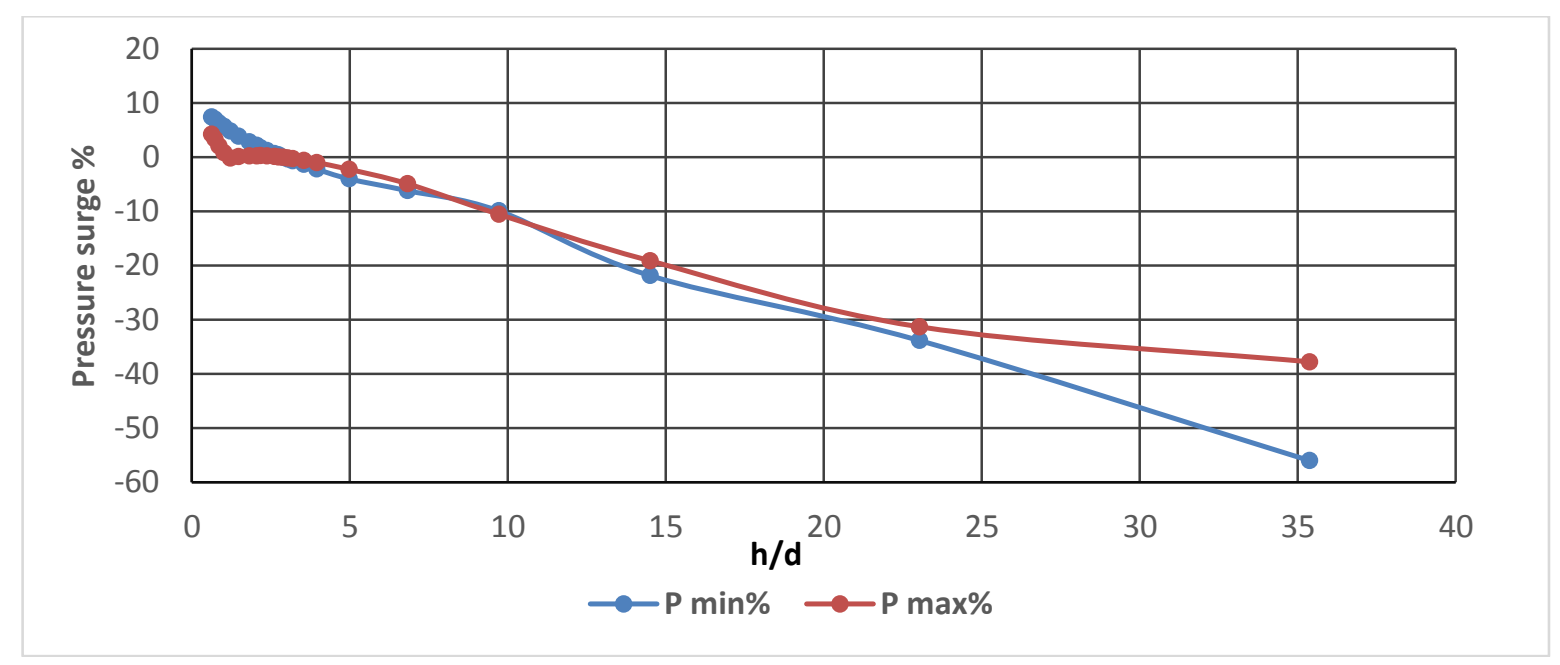

Figure 4 Change in pressure due to change in the ratio $\mathrm{h} / \mathrm{d}$ at the weak point.

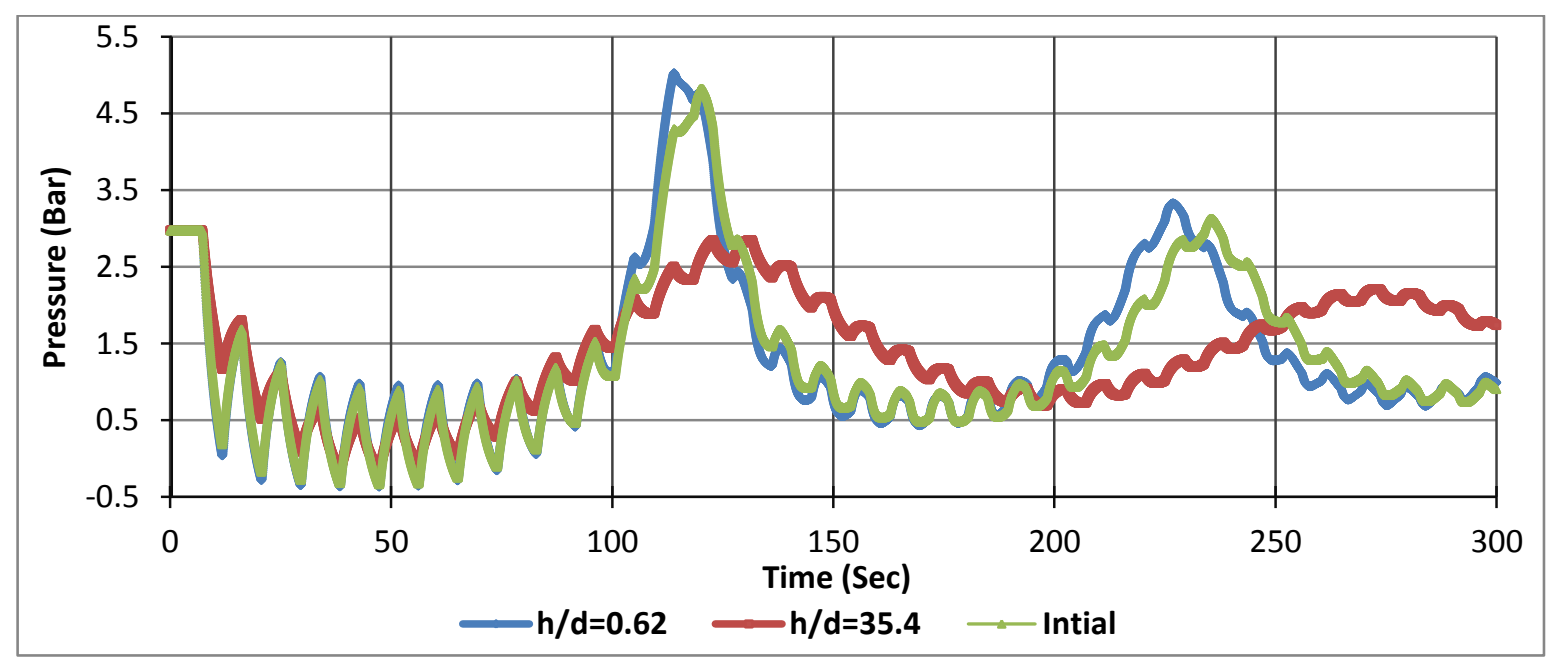

Figure 5 Transient pressure during run time at weak point with a comparison between smallest, largest and the initial ratio $\mathrm{h} / \mathrm{d}$.

\subsection{Initial air volume in the vessel.}

One of the most important parameter that should be specified from the air vessel designer is the initial air volume of the tank $\left(\mathrm{V}_{\mathrm{ai}}\right)$, however, it did not take its priority in the studies before. In 24 run cases, with tuning the ratio of $\mathrm{V}_{\mathrm{ai}}$ to total tank volume $\mathrm{V}_{\mathrm{t}}$. In order to investigate this effect $\mathrm{V}_{\mathrm{ai}}$ was changed rationing from largest ratio $21.31 \%$ where the $\mathrm{V}_{\mathrm{ai}}$ has a maximum volume and the tank work without emptying from water while working to lowest ratio $0.82 \%$ where $\mathrm{V}_{\mathrm{ai}}$ has minimum volume and the tank almost full off water.

The calculations shows the transient pressures effect have been reduced and get better after increasing the ratio of $\left(\mathrm{V}_{\mathrm{ai}} / \mathrm{V}_{\mathrm{t}}\right)$. Figures 6, 7 illustrates transient pressures calculated by Wanda program as a relation with time at the weak point. Figure 6 illustrates the percent change of the transient pressure with respect to the initial case pressure at the weak point, versus the change in the ratio $\mathrm{V}_{\mathrm{ai}} / \mathrm{V}_{\mathrm{t}}$. This figure shows that by increasing the ratio $\mathrm{V}_{\mathrm{ai}} / \mathrm{V}_{\mathrm{t}}$ from the initial value $19.02 \%$ to the largest ratio $21.31 \%$, maximum and minimum surge pressures decreases gradually to reach $-4.6 \%$ and $16.6 \%$ from the initial case values respectively. Otherwise, by decreasing the ratio $\left(\mathrm{V}_{\mathrm{ai}} / \mathrm{V}_{\mathrm{t}}\right)$ the maximum and minimum surge pressures increases gradually until the ratio of $\left(\mathrm{V}_{\mathrm{ai}} / \mathrm{V}_{\mathrm{t}}\right)$ becomes $14.57 \%$ where the maximum and minimum surge pressures increased by $29.7 \%$ and $34.5 \%$ respectively.

After this ratio $14.57 \%$, the more decrease in the ratio $V_{a i} / V_{t}$ meets a harmful increasing in both maximum and minimum surge pressures where at lowest ratio $0.82 \%$ of $\mathrm{V}_{\mathrm{ai}} / \mathrm{V}_{\mathrm{t}}$ maximum and minimum surge pressures increases from initial case values by $244.9 \%$ and $158.2 \%$ respectively.

Fig 7 illustrates surge pressures at the weak point during run time with a comparison between largest, smallest and initial case of $\left(\mathrm{V}_{\mathrm{a} i} / \mathrm{V}_{\mathrm{t}}\right)$. This figure shows the lowest ratio $0.82 \%$ of $\mathrm{V}_{\mathrm{ai}} / \mathrm{V}_{\mathrm{t}}$ has harmful surge pressures with maximum pressure reaches 16.5 bar at $86 \mathrm{sec}$ and minimum surge pressure reaches -0.996 bar and repeated several times. While in 
case of $\mathrm{V}_{\mathrm{ai}} / \mathrm{V}_{\mathrm{t}} 21.31 \%$ the surge pressures shows a slight change from the initial case where the maximum pressure reaches $4.5 \mathrm{bar}$ at $124 \mathrm{sec}$ and minimum pressure reaches $-0.322 \mathrm{bar}$ at $38 \mathrm{sec}$, which considered as worst case.

\subsection{The connection resistance between vessel and pipeline.}

The connection between the air vessel and piping system is aiming to deliver and receive amount of water needed to eliminating the pressure transient, this connection has fittings such as elbow, valve, even through a pipe diameter reducer. All of these fittings have a pressure resistance and flow direction resistance. A ratio of connection resistance $h_{1 c}$ to the working pressure upstream the vessel $\mathrm{P}_{\mathrm{wi}}$ was studied to investigate its effect. Figures 8,9 illustrates the transient pressure calculated by Wanda program as a relations with time at the weak point.

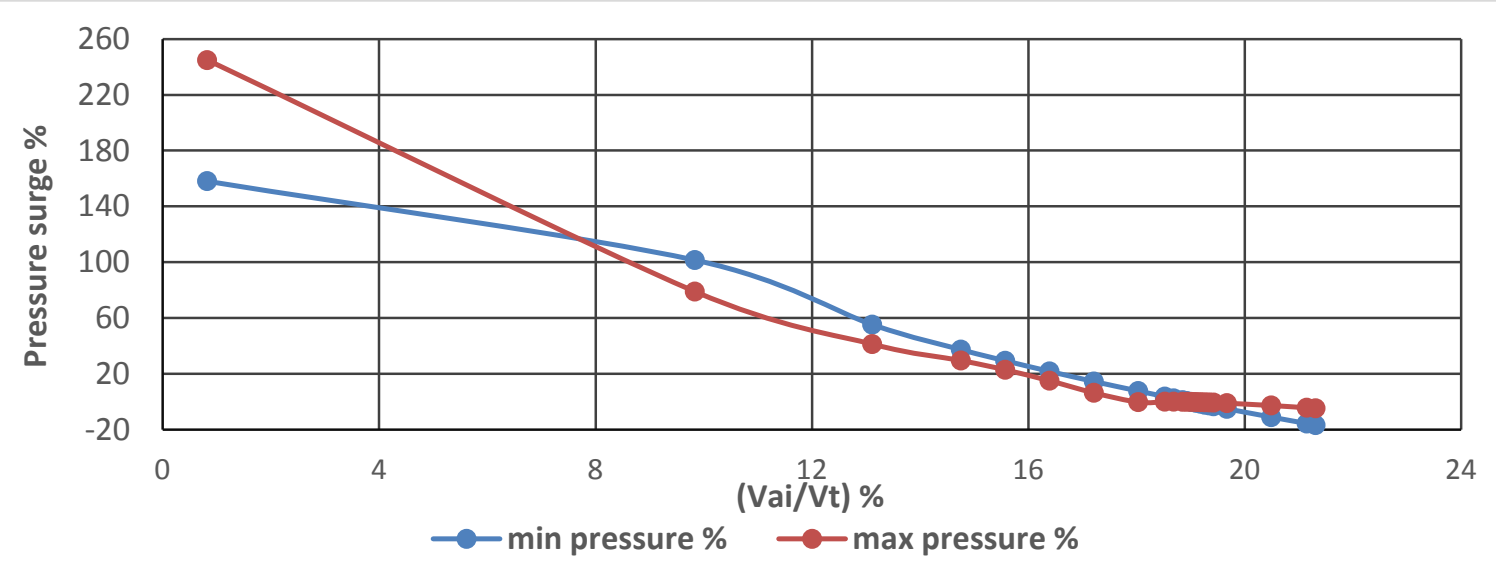

Figure 6 Percent change in pressure due to change in the ratio $\left(\mathrm{V}_{\mathrm{ai}} / \mathrm{V}_{\mathrm{t}}\right)$ at the weak point

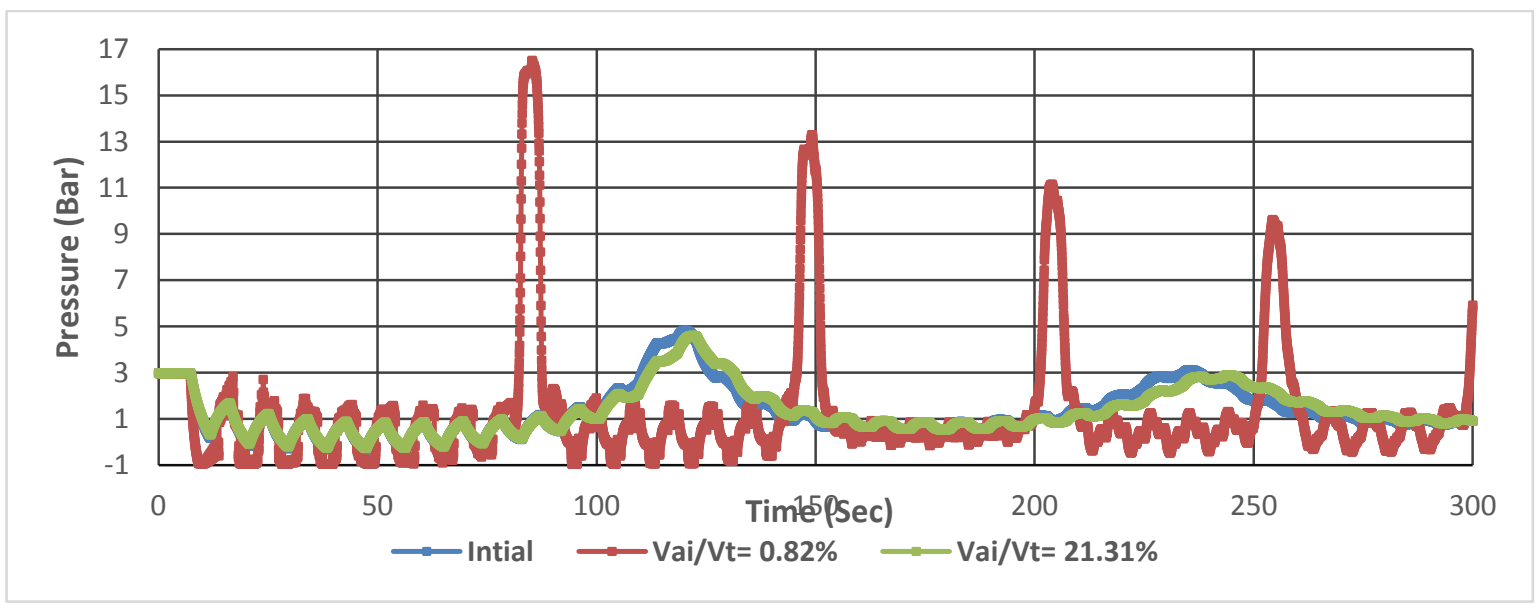

Figure 7 Transient pressure during run time at weak point with a comparison between smallest, largest and the initial ratio $\left(\mathrm{V}_{\mathrm{ai}} / \mathrm{V}_{\mathrm{t}}\right)$.

Figure 8 illustrates the percent change of the transient pressure, with respect to the initial case pressure at the weak point, versus the change in the ratio $\mathrm{h}_{\mathrm{lc}} / \mathrm{P}_{\mathrm{wi}}$. This figure shows that, by increasing the ratio $\mathrm{h}_{\mathrm{lc}} / \mathrm{P}_{\mathrm{wi}}$ to values greater than the initial value $0.74 \%$, the maximum surge pressure decreases until it reaches $-39.47 \%$ at ratio $\mathrm{h}_{\mathrm{lc}} / \mathrm{P}_{\mathrm{wi}}=46.5 \%$. It keeps constant with increasing the ratio $\mathrm{h}_{\mathrm{lc}} / \mathrm{P}_{\mathrm{wi}}$ until reaching $111.93 \%$. On the other hand, by increasing the ratio $\mathrm{h}_{\mathrm{lc}} / \mathrm{P}_{\mathrm{wi}}$ leads the minimum surge pressure to change slightly from the initial pressure case until $\mathrm{h}_{\mathrm{cc}} / \mathrm{P}_{\mathrm{wi}}=7.35 \%$. Then the continuous increase of the ratio, a rapid increase of the minimum surge pressure is occurred until the ratio $\mathrm{h}_{\mathrm{lc}} / \mathrm{P}_{\mathrm{wi}}=33.81 \%$, where minimum pressure increases by $158.2 \%$ and keeps constant until reaching ratio of $111.93 \%$.

Figure 9 illustrates surge pressures at the weak point during run time with a comparison of largest, smallest and initial case of $\left(\mathrm{h}_{\mathrm{lc}} / \mathrm{P}_{\mathrm{wi}}\right)$ those computed by Wanda. This figure shows that at the case $\mathrm{h}_{\mathrm{lc}} / \mathrm{P}_{\mathrm{wi}}=46.5$, the surge pressure fluctuated from +3 bar to a fatal minimum pressure $=-0.996$ bar during the $1 \mathrm{st} 50 \mathrm{sec}$ and damped to 1.5 bar to the finite of the run. The other case of $\mathrm{h}_{\mathrm{lc}} / \mathrm{P}_{\mathrm{wi}}=0.1 \%$ approximately identical with the initial case pressures. Which means, unexpected fluctuation manners for the higher values of $\mathrm{h}_{\mathrm{lc}} / \mathrm{P}_{\mathrm{wi}}$ which will increase to be harmful at the ratio of $\mathrm{h}_{\mathrm{lc}} / \mathrm{P}_{\mathrm{wi}}=$ $46.5 \%$. 


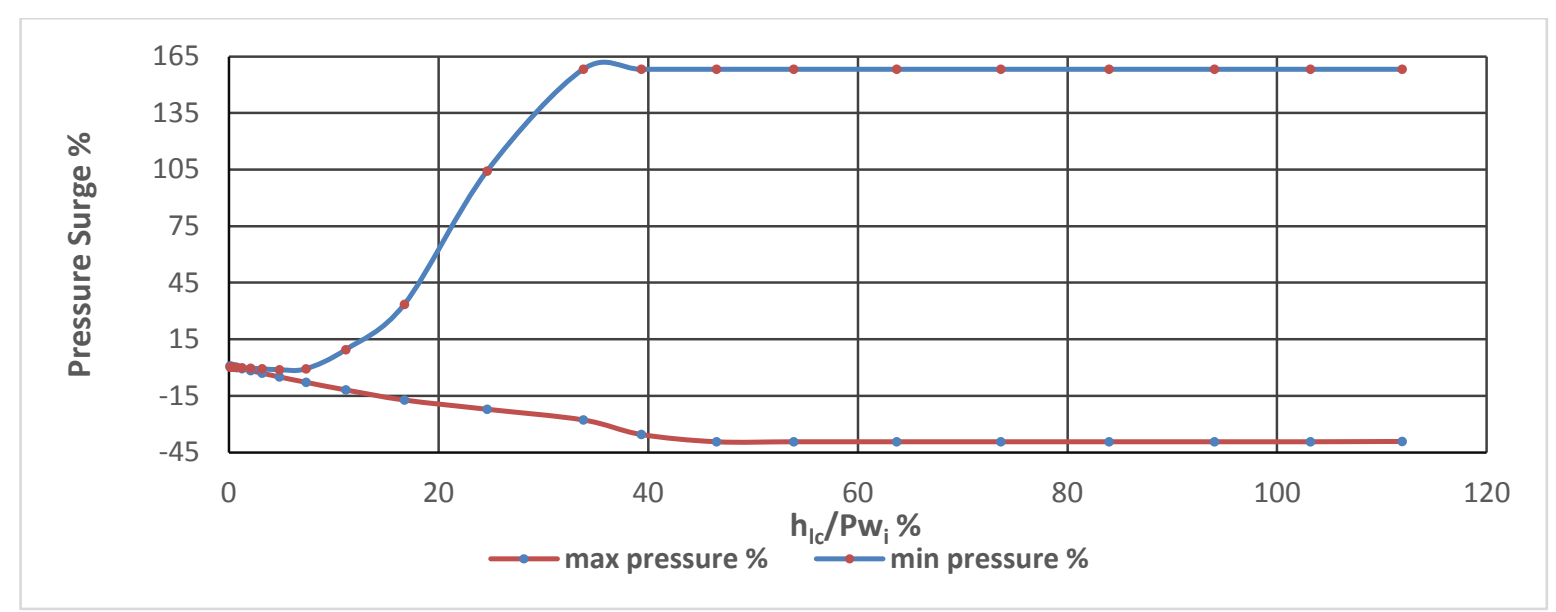

Figure 8 Percent change in pressure due to change in the ratio $\left(\mathrm{h}_{\mathrm{lc}} / \mathrm{P}_{\mathrm{wi}}\right)$ at the weak point.

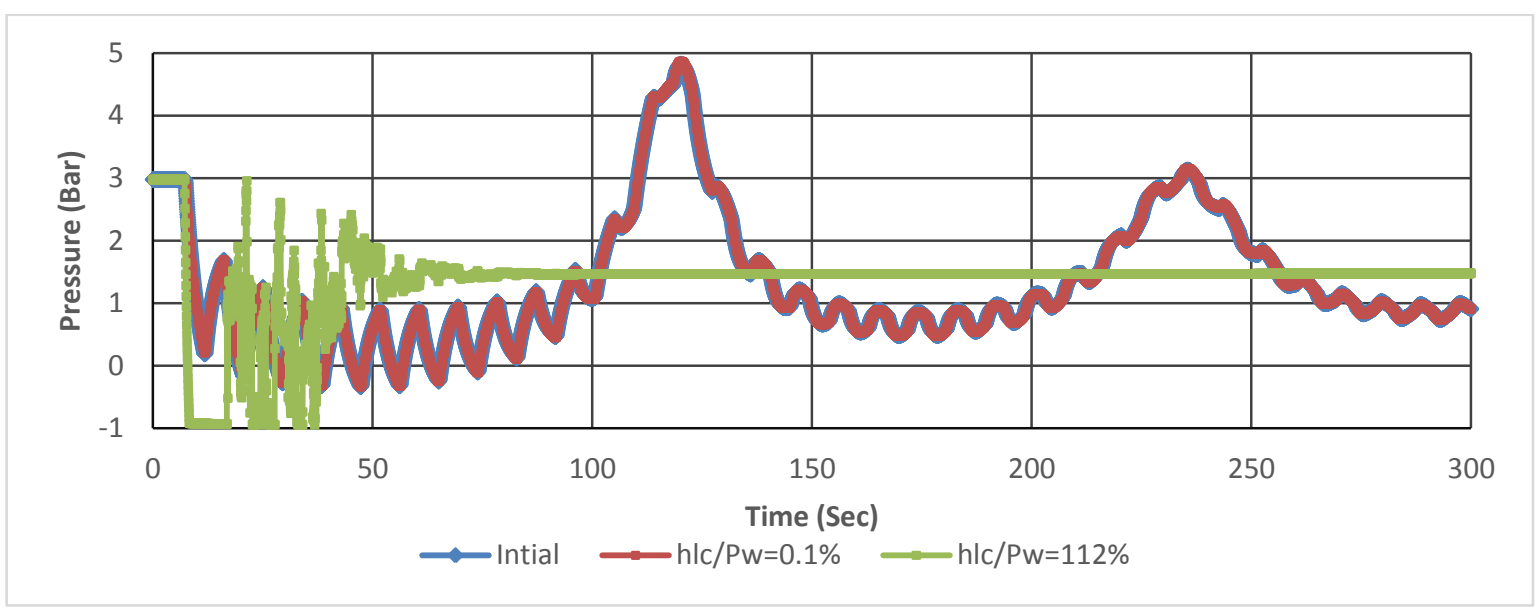

Figure 9 Transient pressure during run time at weak point with a comparison between smallest, largest and the initial ratio $\left(\mathrm{h}_{\mathrm{lc}} / \mathrm{P}_{\mathrm{wi}}\right)$.

\section{CONCLUSION}

The results show that, for a constant air vessel volume, increasing the air vessel height leads to reducing the maximum and minimum pressures by $-37.8 \%$ and $-56 \%$ respectively. While by reducing the air vessel height leads to a small increasing in the maximum and minimum pressures by $4.3 \%$ and $7.4 \%$ respectively. i.e increasing the ratio $\mathrm{h} / \mathrm{d}$ has a great impact on the safety system efficiency and could help for rationing the air vessel total volume as well as the initial coast.

- $\quad$ By tuning the ratio $\mathrm{V}_{\mathrm{ai}} / \mathrm{V}_{\mathrm{t}}$, and decreasing the initial ratio from $19.02 \%$ to $0.1 \%$ leads to increasing the maximum pressure by $245 \%$ and the minimum pressure by $158.2 \%$ from the initial values, which leads to system damage. On the other hand, increasing the ratio to $21.31 \%$ which keeps the air vessel working without emptying from water the maximum and minimum pressures have a small variation and decreases by $-4.6 \%$ and $-16.6 \%$ from the initial case values.

- Designed initial air volume of the air vessel should be specified; any change in the specified initial air volume could make the air vessel out of service and harm the system.

- Increasing the connection resistance between the air vessel and the piping system could harm the system and leads to increase the minimum pressure by $158.2 \%$ and decrease the maximum pressure by $-39.4 \%$ from the initial case values.

- $\quad$ Rationing the connection resistance has a great effect in the safety system and can help for rationing the air vessel total volume as well as the air vessel efficiency.

- Finally, Air vessel parameters are highly sensitive and could harm the system as well as protecting the system. 


\section{RECOMMENDATION}

Based on the study results, the following recommendations are proposed:

- Air vessel parameters need more studies.

- The investigated parameters need to be tested on other systems to assure the results and to be approved to be considered in the designing process.

- An experimental investigation of the transient flow in pipeline is required to compare the results with the results of the mathematical model and help for getting new series of equations help the designers.

\section{NOTATION}

$\begin{array}{llll}- & \mathrm{V}_{\mathrm{t}} & \text { Tank total volume } & \mathrm{m}^{3} \\ - & \mathrm{V}_{\mathrm{ai}} & \text { Initial Air Volume } & \mathrm{m}^{3} \\ - & \mathrm{d} & \text { Diameter of vessel } & \mathrm{m} \\ - & \mathrm{h} & \text { Height of vessel } & \mathrm{m} \\ - & \mathrm{P}_{\min } & \text { Minimum turbulent pressure } & \mathrm{Bar} \\ - & \mathrm{Pi}_{\min } & \text { Initial system minimum turbulent pressure } & \mathrm{Bar} \\ - & \mathrm{P}_{\max } & \text { Maximum turbulent pressure } & \mathrm{Bar} \\ - & \mathrm{P}_{\max } & \text { Initial system maximum turbulent pressure } & \mathrm{Bar} \\ - & \mathrm{P}_{\mathrm{w}} & \text { Steady working pressure } & \mathrm{Bar} \\ - & \mathrm{P}_{\mathrm{wi}} & \text { Steady working pressure, initial system } & \mathrm{Bar} \\ - & \text { Percent change in minimum pressure } \% & =\left(\mathrm{P}_{\min }-\mathrm{Pi}_{\min }\right) / \mathrm{Pi}_{\min } * 100 & \\ - & \text { Percent change in maximum pressure } \% & =\left(\mathrm{P}_{\max }-\mathrm{Pi}_{\max }\right) / \mathrm{Pi}_{\max } * 100 & \end{array}$

\section{REFERENCES}

[1] Alexandre K. Soares et.al. 2009. Unsteady Flow with Cavitation in Viscoelastic Pipes. International Journal of Fluid Machinery and Systems. Vol. 2, No. 4, October-December 2009. Pp,269-277.

[2] Simpson, A. R. and Bergant, A., 1994, "Numerical comparison of pipe-column-separation models," Journal of Hydraulic Engineering, ASCE, Vol. 120, No. 3, pp. 361-377.

[3] Itissam, O. Ahmed, S. Karima, O. Driss. 2013. Sizing the Protection Devices to Control Water Hammer Damage. International Journal of Civil, Architectural Science and Engineering Vol:7 No:11, pp,415-420.

[4] M.A. Bouaziz, et,al. 2014. Water hammer effects on a gray cast iron water network after adding pumps. Engineering Failure Analysis 44, pp,1-16.

[5] A.S. Tijsseling. 2007. Water hammer with fluid-structure interaction in thick-walled pipes. Computers and Structures 85 (2007). Pp, 844-851.

[6] Khamlichi , L. Jezequel and F. Tephany. Elastic-plastic water hammer analysis in piping systems. Wave Motion 22 (1995) 279-295.

[7] Arash Niroomandi , Seyed Mahmood Borghei and Asghar Bohluly. 2012. Implementation of Time Splitting Projection Method in water hammer modeling in deformable pipes. International Journal of Pressure Vessels and Piping 98 (2012). Pp, 30-42.

[8] Fathy M. Radwa, El Sayed T., Hamdy W. and Ramdan K. 2011. Computer analysis of the different water hammer protection systems. Engineering Research Journal Faculty of Engineering, Minoufiya University.

[9] Eman Fawzi. 2011. Improving Design of Irrigation Pipeline Networks, Egypt 2011.

[10] Robert Keller. 2014. Investigation of Severe Water Hammer in a Large Pump Station - Case Study. Pipelines 2014, ASCE 2014, pp, 1392-1401.

[11] Allievi, L., "Theory of water Hammer", (Translated by E.E. Halmos), Riccardo Garon Rormme, 1913. Allievi, L., 1913, “Teoria del colpo d'ariete,' Atti Collegio Ing. Arch. English translation by Halmos EE 1929!, “The Theory of Waterhammer," Trans. ASME.

[12] Angus, Robert W., 1935, Simple Graphical Solution for Pressure Rise in pipes and Pump discharge lines, J. Eng. Inst., Canada, pp. 72-81.

[13] Joukovsky, N., "Water Hammer" (Translated by Miss O. Simin), Proc. Am. Watervords Assoc. Vol. 24, pp. 341-424, 1904.

[14] Streeter, V. L., and E.B. Wylie,1967, Hydraulic Transient, McGraw-Hill Book Co. (Now sold by University Microfilms, Ann Arbor, Michigan), 1967.

[15] Wylie, E.B., Streeter, V.L., and Suo, L., 1993, Fluid Transients in Systems, McGraw-Hill, 1993.

[16] Anton Bergant et al., 2008. Parameters affecting water-hammer wave attenuation, shape and timing Part 1: Mathematical tools. Journal of Hydraulic Research Vol. 46, No. 3 (2008), pp. 373-381. 
[17] Dídia Covas, et al. 2010. The dynamic effect of pipe-wall viscoelasticity in hydraulic transients Part II — model development, calibration and verification. Journal of Hydraulic Research, 43:1, 56-70.

[18] David Stephenson, Fellow, ASCE. 1997. Effects of air valves and pipe work on water hammer pressures. Journal of Transportation Engineering. 1997.123. pp,101-106.

[19] P.U. Akpan,et al. 2015. Modelling and transient simulation of water flow in pipelines using WANDA Transient software. Ain Shams Engineering Journal (2015).

[20] Simon Sidmak. 2016. Elastic-plastic behaviour of welded joints during loading and unloading of pressure vessels. 21st European Conference on Fracture, ECF21, 20-24 June 2016, Catania, Italy.

[21] Vahid Rezaei, Melih Calamak, and Zafer Bozkus. 2017. Performance of a Pumped Discharge Line with Combined Application of Protection Devices Against Water Hammer. KSCE Journal of Civil Engineering (2017) 21(4), pp, 1493-1500. 